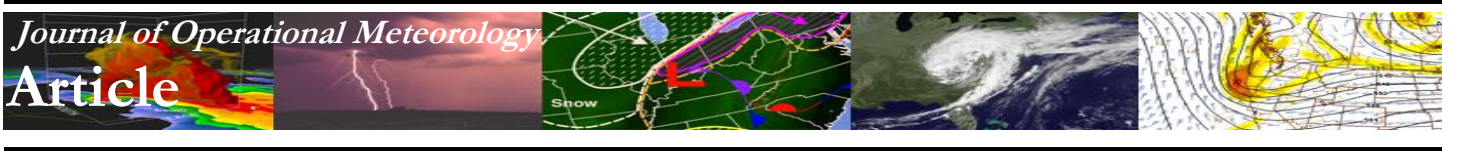

\title{
Application of Radiosonde Ascent Rate Variations to Detect Atmospheric Turbulence Affecting Aircraft
}

\author{
WILLIAM H. BLACKMORE \\ Upper-air Observations Program, NOAA National Weather Service Headquarters, Silver Spring, Maryland \\ RYAN D. KARDELL \\ NOAA/National Weather Service Weather Forecast Office, Springfield, Missouri
}

(Manuscript received 29 October 2013; review completed 24 January 2014)

\begin{abstract}
Atmospheric turbulence is a significant hazard to aircraft, comprising $11 \%$ of weather-related aircraft accidents in recent decades. Research conducted in the late 1960s indicated a potential association between radiosonde ascent rates and aircraft turbulence, suggesting a potential way to produce proxy observations of turbulence. Recent advances in computing technology have allowed for a more thorough reexamining of these research findings that utilizes more available data.

A total of 441 matched cases retrieved from $3.5 \mathrm{yr}$ of sounding and pilot report data were analyzed. Statistical analysis of the data shows a clear relationship (with significance exceeding the $\alpha<0.01$ level) between observed cases of moderate or greater turbulence and increased variations in ascent rate over a given depth.
\end{abstract}

\section{Introduction}

Atmospheric turbulence remains a significant hazard to aircraft. A 10-yr study, from 1992 to 2001, by the National Aviation Safety Data Analysis Center (NASDAC; 2004) reported 509 aircraft accidents resulting from turbulence that comprised $11 \%$ of the total weather-related aviation accidents. Some of these accidents caused serious injuries to passengers and crew. Numerical weather model guidance, on-board aircraft radar, pilot reports (PIREPs), and other methods are used by weather forecasters to help identify areas of light to severe turbulence caused by wind shear, convection, and land topography.

Research by Hodge (1967; hereafter cited as Hodge) found that abrupt variations in radiosonde ascent rate could be used to detect layers of turbulence affecting aircraft. Using archived data, Hodge found that, in most cases, PIREPs of turbulence occurred near the same altitude where a nearby radiosonde sounding showed a large change in ascent rate within a layer. However, in the 1960s, National Weather Service (NWS) radiosonde soundings were still processed mostly by hand and it would have been too time consuming to create a radiosonde ascent rate dataset for use as an aide to operational aviation forecasts. It was not until the mid-1980s that data processing of the sounding was entirely automated.

With the network deployment of the Radiosonde Replacement System (RRS) by the NWS beginning in August 2005, radiosonde pressure, temperature, humidity, winds, geopotential and global positioning system (GPS)-derived height, latitude, and longitude are collected and processed every second as documented in Bower (2005). The RRS allows the observer to view many types of real-time data plots to help quality control the data prior to dissemination and archiving. These include a plot of 1-s and smoothed 1min ascent rates with height.

This paper seeks to expand on the work done by Hodge. A larger dataset of radiosonde ascent data and PIREPs over a 3.5-yr period was analyzed. It will be shown that radiosonde ascent rate variations can be an indicator of turbulence affecting aircraft and, thus, could be used as a potential component in the development of real-time proxy observations of turbulence affecting aircraft. 


\section{Balloon characteristics and calculation of ascent rate}

As of 2013, NWS upper-air stations use a balloon weighing about $600 \mathrm{~g}$. The balloons typically are inflated with $1.7-2.0 \mathrm{~m}^{3}\left(60-71 \mathrm{ft}^{3}\right)$ of either hydrogen or helium gas. When inflation is completed, the balloon is mostly spherical in shape and has a diameter of about $1.5 \mathrm{~m}$. At a typical aircraft cruising altitude of $9144 \mathrm{~m} \mathrm{(30} \mathrm{kft),} \mathrm{the} \mathrm{balloon} \mathrm{has} \mathrm{expanded} \mathrm{to} \mathrm{about} 2$ $\mathrm{m}$ in diameter. The balloons typically have an average ascent rate between 250 and $350 \mathrm{~m} \mathrm{~min}^{-1}$ (or 4.2 and $5.8 \mathrm{~m} \mathrm{~s}^{-1}$ ) and burst at heights around $30 \mathrm{~km}$. Possible causes for variations in balloon ascent rate not associated with turbulence in the atmosphere are as follows:

- The shape of the balloon as it rises is not always a perfect sphere. Some balloons will ascend with a somewhat flattened top, slowing the ascent rate, while others will rise faster because they have a more rounded top.

- The dimensions of the balloon and the subsequent ascent rate can change as the balloon rises and expands unevenly owing to thick and thin areas in the balloon membrane.

- Ice accretion on the balloon can significantly lower ascent rates for much of the observation.

- The temperature of the gas in the balloon may suddenly become different from the temperature of the surrounding air, causing a variation in the buoyancy and ascent rate of the balloon. Such conditions would occur if the balloon entered a strong temperature inversion (e.g., the tropopause).

- Rising balloons may experience abrupt changes in drag because of shedding of vortices that develop in their wake (Gallice et al. 2011).

RRS soundings provide 1-s geopotential heights derived from the radiosonde pressure, temperature, and relative humidity (PTU) data. To reduce noise from the radiosonde sensors, the 1-s PTU data were smoothed over a moving 9-s interval. Balloon ascent rates were calculated and plotted from the difference in derived geopotential height from one second to the next (method 1). Smoothed 1-s ascent rates also were obtained from the geometric heights derived by the radiosonde GPS sensor. They were smoothed over a 60-s interval to help remove the pendulum motion of the ascending radiosonde and other noise (method 2). Calculated geopotential heights are independent of those derived from the GPS data, and the two measurements can be used to verify that the ascent rates measured are accurate. In this study, ascent rates derived from the geopotential heights were used (i.e., method 1).

\section{Data and methods}

Archived PIREPs issued between March 2009 and September 2012 were examined for reports of negligible (NEG) turbulence and continuous moderate (MOD) to severe (SEV) turbulence between 6096 and $12192 \mathrm{~m}$ (20 and $40 \mathrm{kft}$ ). The PIREP archives for this time period had no reports of extreme (EXT) turbulence. Wolff et al. (2008) found that proximal NEG and MOD or greater turbulence PIREPs were very consistent with each other, and thus they were examined in this study. Light (LGT) turbulence reports were less consistent with each other and thus were omitted in the analysis. The layer between 6096 and $12192 \mathrm{~m}$ (20 and $40 \mathrm{kft}$ ) was chosen to help eliminate turbulence reports resulting from small-scale or local turbulence caused by topography or convective clouds. All aircraft types that fly at these altitudes were included. These reports were matched with archived NWS radiosonde observations taken nearby.

Hodge matched radiosonde observations with a PIREP if they were $185 \mathrm{~km}(100 \mathrm{n} \mathrm{mi})$ or less apart and taken within $3 \mathrm{~h}$ of each other. Hodge defined a good match as when the variation in ascent rates between adjacent layers was $25 \%$ or greater of the average ascent rate for the observation. Adjacent layers were defined as $610-$ to $762-\mathrm{m}$ (2- to $2.5-\mathrm{kft}$ ) thick. In this study, a match occurred if the PIREP was recorded during the first hour of the radiosonde flight and was recorded at a location within $46 \mathrm{~km}(25 \mathrm{n} \mathrm{mi})$ of the radiosonde release site. Based on these thresholds, 441 matched observations were found compared to the 190 observations used by Hodge. There were 266 matches of a PIREP and a nearby radiosonde observation for MOD to SEV turbulence and 175 matches for NEG turbulence. All the matches occurred in the contiguous United States. Although Hodge excluded any observations within $100 \mathrm{~km}$ of thunderstorm activity, such observations were included in this analysis to study the impact of thunderstorm-generated turbulence on the observations.

The radiosonde data were processed to provide 1-s radiosonde ascent rate data smoothed over a moving 9 -s period. Next, the ascent rate variation, defined as the difference between the maximum and minimum 
a) Flight Date: 10/07/2010 00z

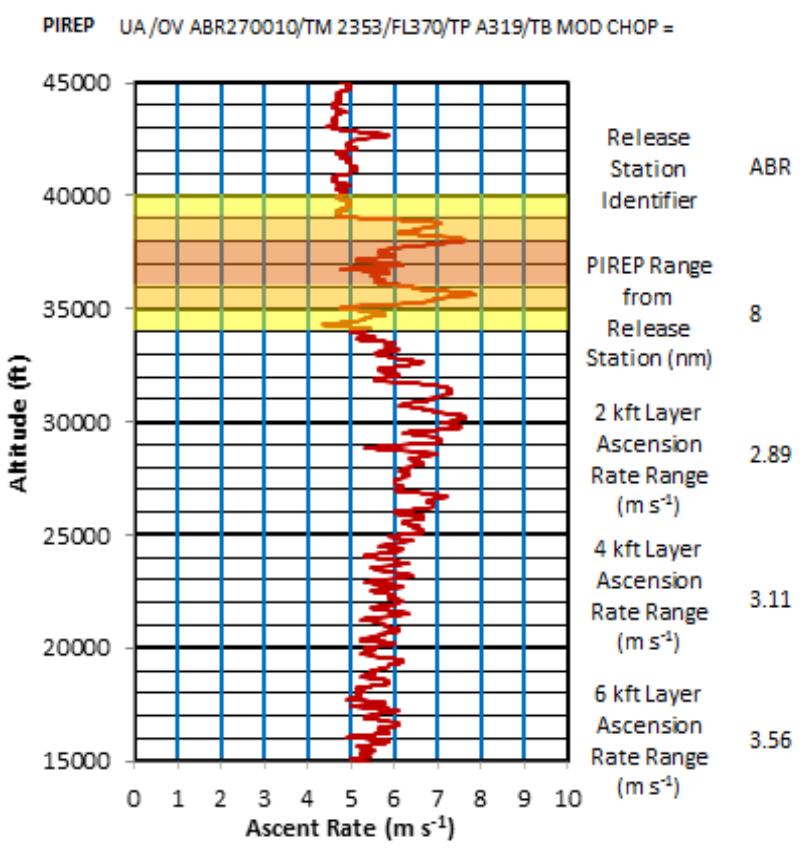

b) Flight Date: 05/28/2010 $12 z$

PIREP UA/OV BUF/TM 1148/FL340/TP B763/SK SKC/TA M50/WV 28735KT/TB NEG=

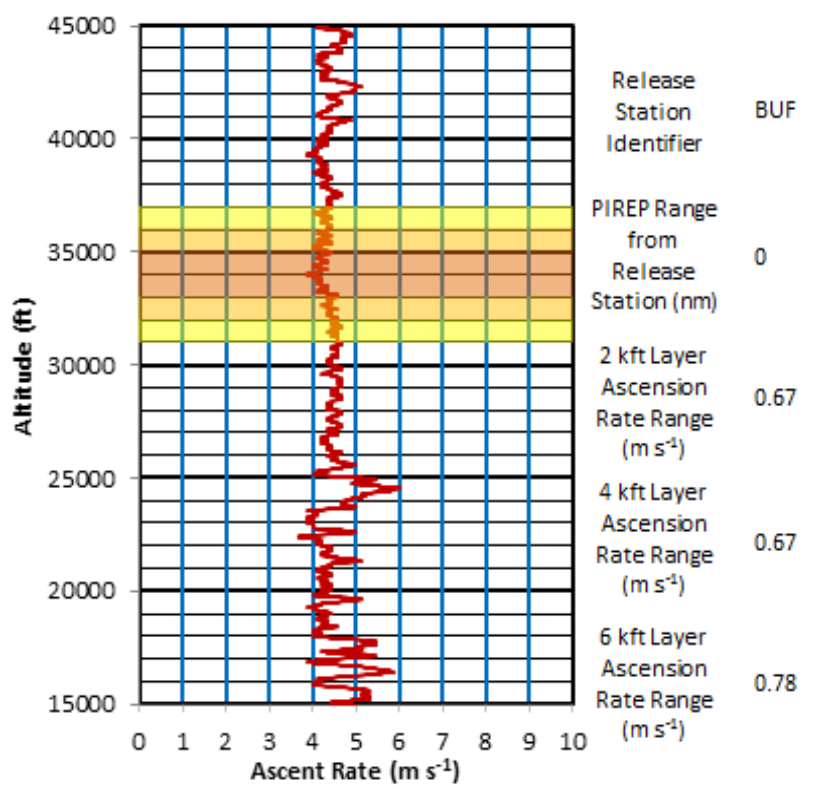

Figure 1. Cases where (a) MOD or greater turbulence was associated with strong ascent rate variation and (b) NEG turbulence was reported with minor variations of ascent rate. The $x$-axis is ascent rate in $\mathrm{m} \mathrm{s}^{-1}$ and the $y$-axis is height in $\mathrm{ft}$. Also shown is the associated PIREP for (a) moderate chop at $37 \mathrm{kft}$ and (b) no turbulence at $34 \mathrm{kft}$. Maximum variation of the ascent rate in 2-, 4-, and 6-kft layers is shown as shaded areas. Click image for an external version; this applies to all figures hereafter. values in a layer, was calculated over 610-, 1219-, and 1829-m (2-, 4-, and 6-kft) layers centered at the altitude of the PIREP. These layers were chosen to determine which layer(s) provided the best match of the ascent rate variation to the associated turbulence report. The ascent rate data were plotted versus height and compared with the associated PIREP. Note that the radiosonde heights were calculated in geopotential feet, while altitudes in PIREPs were calculated as pressure altitude.

\section{Results and discussion}

Figure 1a shows an example of radiosonde ascent rates versus altitude taken at the NWS upper-air station in Aberdeen, South Dakota. The associated PIREP of MOD chop turbulence at $11278 \mathrm{~m} \mathrm{(37} \mathrm{kft)}$ was taken nearby and within $1 \mathrm{~h}$ after radiosonde release. For reference, 610-, 1219-, and 1829-m (2-, 4-, and 6-kft) layers, centered at the altitude of the PIREP, are shown in colored shading. Note that between 10668 and $11887 \mathrm{~m} \mathrm{(35}$ and $39 \mathrm{kft})$ there were abrupt variations in the ascent rate, with a range in the three layers of around $3 \mathrm{~m} \mathrm{~s}^{-1}$.

Radiosonde ascent rates taken at the NWS upperair station in Buffalo, New York, are shown in Fig. 1b. The associated PIREP of NEG turbulence at $10363 \mathrm{~m}$ (34 kft) was taken very close by and around $45 \mathrm{~min}$ after balloon release. In this example, the ascent rates varied very little from $7620 \mathrm{~m}$ ( $25 \mathrm{kft})$ to $12192 \mathrm{~m}$ (40 $\mathrm{kft}$ ) and the maximum variation of the ascent rate in the three layers was $<1 \mathrm{~m} \mathrm{~s}^{-1}$.

Prima facie analysis of ascent rate plots from the 441 matched observations indicated that when radiosonde ascent rates vary abruptly, the balloon is encountering turbulence or vertical motions of sufficient magnitude that may affect aircraft flying at or near the same altitude. Conversely, if the radiosonde ascent rate variations are small, turbulence may not be present in the layer the balloon is passing through. This is in general agreement with Hodge. However, this relationship was not seen in all cases examined. Figures $2 \mathrm{a}$ and $2 b$ show examples of both a false negative and $a$ false positive, respectively. More will be discussed about false identifications below.

All 441 matched observations were tabulated to determine the relationship between the ascent rate variation in a layer and the reported turbulence in the PIREP. Figure 3 shows histograms of the counts of maximum ascent rate variations from 0.0 to $6.5 \mathrm{~m} \mathrm{~s}^{-1}$ in 610-, 1219-, and 1829-m (2-, 4-, and 6-kft) layers. 


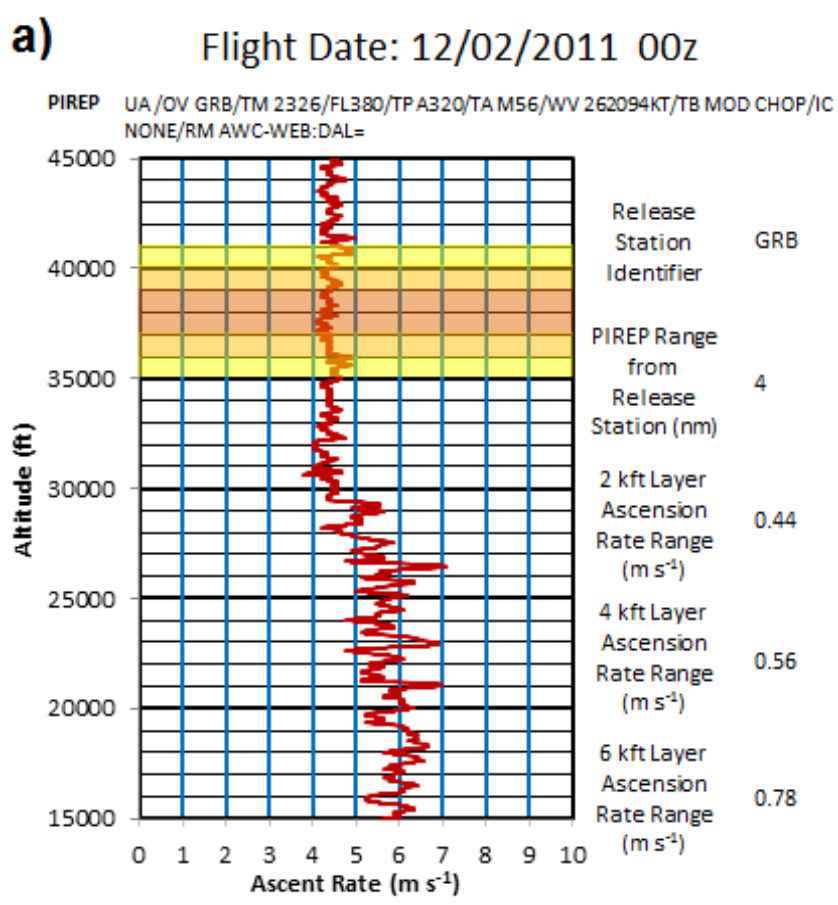

b)

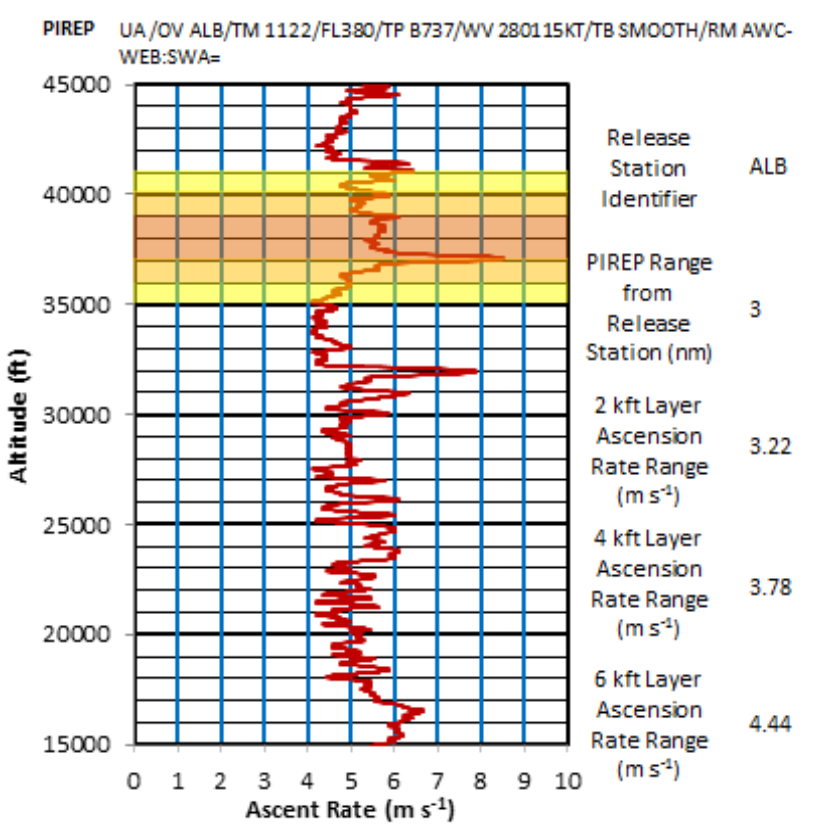

Figure 2. Examples of (a) false negative and (b) false positive cases. All other labeling is the same as in Fig. 1. Moderate chop in (a) was reported at $38 \mathrm{kft}$ with small variations in ascent rate, and in (b) no turbulence was reported at $38 \mathrm{kft}$, but there were large variations in ascent rate.

Because of the subjectivity of the PIREP data, discussed later in this paper, LGT turbulence and occasional (OCNL) turbulence reports were not used.
Initial analysis of the data depicted in Fig. 3 indicated a relationship between ascent rate variations in radiosonde data and the occurrence of MOD to SEV aircraft turbulence. However, false negatives and false positives were not uncommon in the analysis. Some potential explanations for false negatives and false positives are as follows:

- The balloon ascent rate was affected by one or more factors (balloon shape, ice accretion, ambient air temperature, vortex shedding, etc.) noted earlier in section 2.

- The turbulence was strong enough to affect the balloon, but not a larger, heavier aircraft. This question could be addressed by a more detailed engineering study in the future.

- The turbulence was temporally and spatially small (e.g., associated with thunderstorms) and was only detected by the aircraft or radiosonde.

- The approach utilized within this study was to assume that radiosonde observations were representative of conditions for PIREPs within $46 \mathrm{~km}(25 \mathrm{n}$ $\mathrm{mi}$ ) of the radiosonde release point. The drift of the radiosonde away from the release point was not taken into account. Future studies could use the actual location of the radiosonde in flight to verify that it is close to the location of the PIREP.

- Pilots tend to fly around convection while radiosondes do not.

- Radiosonde heights are calculated as geopotential height, while altitudes in PIREPs are calculated as pressure altitude. The differences between the two heights can be several hundred feet.

Finally, PIREPs may not always depict a consistent representation of turbulence conditions because of the subjectivity of the reporting process (Schwartz 1996; Wolff et al. 2008). General criteria for various turbulence intensities (Federal Aviation Administration 2012) are as follows: light (loose objects in aircraft remain at rest); moderate (unsecured objects are dislodged, occupants feel definite strains against seat belts and shoulder straps); severe (occupants thrown violently against seat belts, momentary loss of aircraft control, unsecured objects tossed about); and extreme (aircraft is tossed violently about, impossible to control, may cause structural damage). These criteria have a significant level of subjectivity and will vary somewhat depending upon the pilot's personal perceptions of the turbulence event. 
a)
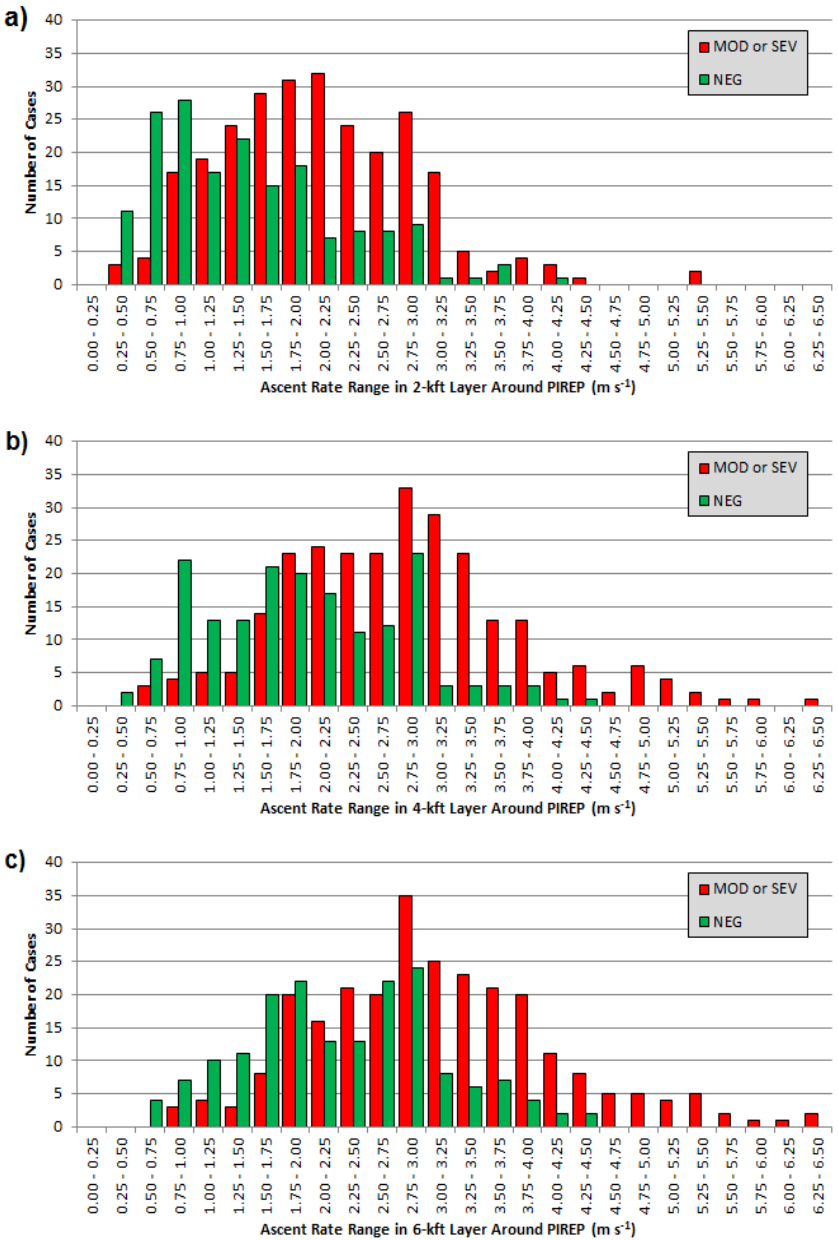

Figure 3. Histogram of maximum ascent rate variations in (a) 2$\mathrm{kft}$, (b) 4-kft, and (c) 6-kft layers for NEG turbulence cases (green) and MOD or SEV turbulence cases (red). The $x$-axis is the ascent rate range in $0.25 \mathrm{~m} \mathrm{~s}^{-1}$ increments.

\section{Hypothesis tests and results}

The alternative hypothesis proposed by this paper is that atmospheric turbulence capable of producing MOD to SEV turbulence PIREPs can be detected by variations in radiosonde ascent rate. This posited relationship makes intuitive sense given that both aircraft and balloons are objects that can be buffeted by atmospheric turbulence. The null hypothesis is that turbulence cannot be detected by comparing ascent rates in which turbulence was occurring with ascent rates in which turbulence was not occurring. For the purposes of this study, $p$ values that fall below a level of $\alpha=0.01$ will be considered significant.

To test the basic validity of this hypothesis, a onetailed difference of sample means test was performed (Wilks 1995, p. 122). The control dataset consisted of 175 samples where NEG turbulence was reported. The test dataset consisted of 266 samples where MOD or SEV turbulence was reported. Both of these datasets are of adequate size (much greater than 30 cases) to perform reliable statistical analysis. Table 1 lists the various statistics used in the analysis for the $1829-\mathrm{m}$ (6-kft) layer dataset. The observed difference of sample means was $0.92 \mathrm{~m} \mathrm{~s}^{-1}$, which is about nine standard deviations of the difference of sample means and much greater than the critical value of $0.233 \mathrm{~m} \mathrm{~s}^{-1}$ at the significance level of $\alpha=0.01$. The 1829-m (6$\mathrm{kft}$ ) layer dataset is being discussed in detail here, in part because of the favorable results illustrated in Fig. 3c. Nevertheless, the analysis for all three layers in Fig. 3 yielded $p$ values well below the $\alpha=0.01$ predetermined threshold.

Table 1. Statistics used for the difference of sample means hypothesis test where cases of MOD and SEV turbulence $(t)$ are compared with cases of NEG turbulence or "smooth" conditions $(s)$. Considering the difference of population means $\left(\mu_{t-s}\right)$, the null hypothesis for this test is that $\mu_{t-s}=0$ with the alternative hypothesis being that $\mu_{t-s}>0$.

\begin{tabular}{|c|c|c|}
\hline Sample Statistic & MOD \& SEV dataset & NEG dataset \\
\hline Sample size (n) & $\mathrm{n}_{\mathrm{t}}=266$ & $\mathrm{n}_{\mathrm{s}}=175$ \\
\hline $\operatorname{Mean}(\bar{x})$ & $\bar{x}_{t}=3.19 \mathrm{~m} \mathrm{~s}^{-1}$ & $\bar{x}_{s}=2.27 \mathrm{~m} \mathrm{~s}^{-1}$ \\
\hline Variance $\left(\mathrm{s}^{2}\right)$ & $\mathrm{s}_{\mathrm{t}}^{2}=1.48 \mathrm{~m}^{2} \mathrm{~s}^{-2}$ & $\mathrm{~s}_{\mathrm{s}}^{2}=0.70 \mathrm{~m}^{2} \mathrm{~s}^{-2}$ \\
\hline $\begin{array}{l}\text { Standard deviation } \\
(\mathrm{s})\end{array}$ & $\mathrm{s}_{\mathrm{t}}=1.22 \mathrm{~m} \mathrm{~s}^{-1}$ & $\mathrm{~s}_{\mathrm{s}}=0.84 \mathrm{~m} \mathrm{~s}^{-1}$ \\
\hline \multicolumn{3}{|c|}{ Difference of Sample Means Statistics } \\
\hline \multicolumn{2}{|c|}{$\begin{array}{l}\text { Difference of sample means: } \\
\qquad \overline{\mathrm{x}}_{t-s}=\overline{\mathrm{x}}_{t}-\overline{\mathrm{x}}_{s}\end{array}$} & $0.92 \mathrm{~m} \mathrm{~s}^{-1}$ \\
\hline \multicolumn{2}{|c|}{$\begin{array}{l}\text { Variance of difference of sample means: } \\
\qquad s^{2}{ }_{t-s}=\frac{s^{2} t}{n_{t}}+\frac{s^{2} s}{n_{s}}\end{array}$} & $0.01 \mathrm{~m}^{2} \mathrm{~s}^{-2}$ \\
\hline \multicolumn{2}{|c|}{$\begin{array}{l}\text { Standard deviation of difference of sample means: } \\
\qquad \mathrm{s}_{t-s}=\sqrt{\frac{\mathrm{s}^{2} t}{\mathrm{n}_{\mathrm{t}}}+\frac{\mathrm{s}^{2} s}{\mathrm{n}_{\mathrm{s}}}}\end{array}$} & $0.10 \mathrm{~m} \mathrm{~s}^{-1}$ \\
\hline \multicolumn{2}{|c|}{$\begin{array}{l}\text { Critical difference of sample means value }\left(\overline{\mathrm{x}}_{\alpha}\right) \text { for } \\
\text { significance level }(\alpha=0.01) \text { using corresponding } \\
\text { z table value }\left(z_{\alpha}=2.33\right) \text { : }\end{array}$} & $\begin{array}{l}\overline{\mathrm{x}}_{\alpha}=\mathrm{z}_{\alpha} \times \mathrm{s}_{\mathrm{t}-\mathrm{s}}= \\
2.33 \times 0.10 \mathrm{~m} \mathrm{~s}^{-1} \\
=0.233 \mathrm{~m} \mathrm{~s}^{-1}\end{array}$ \\
\hline \multicolumn{2}{|c|}{$\begin{array}{l}\text { Probability of falsely rejecting null hypothesis: } \\
\qquad p \text { value }\left(P_{0}\right)\end{array}$} & $\begin{aligned} \bar{x}_{t-s} & \bar{x}_{\propto} \\
\stackrel{\text { yields }}{\longrightarrow} & P_{o} \ll \mathbf{0 . 0 1}\end{aligned}$ \\
\hline
\end{tabular}


The results of the differences of sample means hypothesis test show that the null hypothesis - that atmospheric turbulence capable of producing MOD to SEV turbulence PIREPs cannot be detected by radiosonde ascent rate data-is very likely to be false and can reasonably be rejected. These results are encouraging, suggesting that further research of this subject is warranted.

To determine if local turbulence caused by thunderstorms affected the results, the 441 cases were reanalyzed to look at only those cases that occurred between 31 October and 1 March. Thunderstorm activity is far less likely to occur during these months. There were 145 cases, and the statistics showed very little change from those generated with the 441 cases. Nonetheless, future studies should include a close look at the location of the radiosonde and PIREP in relation to the thunderstorm (if any) as seen in radar or satellite imagery.

Despite the potential for false negatives and false positives (e.g., Fig. 2), additional analysis of the data suggests that some meaningful probabilistic inferences may be made from observed ascent rate data. Figure 4 shows an estimation of probability of occurrence of MOD to SEV turbulence. This was done by adjusting the frequency of observation for both the NEG and MOD to SEV turbulence datasets such that they are normalized to equal sample sizes. Next, the proportion of observed turbulence hits in a data bin to the total observations in a data bin was tabulated.

The noise in the data is considerable, but a notable trend is captured by the linear fit. The estimated probability of MOD to SEV turbulence increases with increased variation of ascent rates within a $1829-\mathrm{m}$ layer $\pm 914 \mathrm{~m}$ of a PIREP (6-kft layer, $\pm 3 \mathrm{kft}$ ), and at a rate of about $20 \%$ per $1 \mathrm{~m} \mathrm{~s}^{-1}$ increase of ascent rate change. Further research that utilizes larger sample sizes, or possibly incorporates wind and temperature data collected by the radiosonde, may diminish the noise and reveal any nonlinear relationships that may better represent the probabilistic relationship.

\section{Ascent rate observations above $12.2 \mathrm{~km}(40 \mathrm{kft})$}

Although the focus of this research is the 6096- to 12 192-m (20- to 40-kft) layer, some interesting observations have been made of radiosonde ascent rates above $12192 \mathrm{~m}$ (40 kft) that are worth briefly noting here. Commercial aircraft do not typically fly above 12 $192 \mathrm{~m} \mathrm{(40} \mathrm{kft),} \mathrm{and} \mathrm{thus} \mathrm{PIREPs} \mathrm{are} \mathrm{very} \mathrm{rare} \mathrm{above}$ that level. However, radiosonde observations often

\section{a)}

Turbulence Probability Approximation

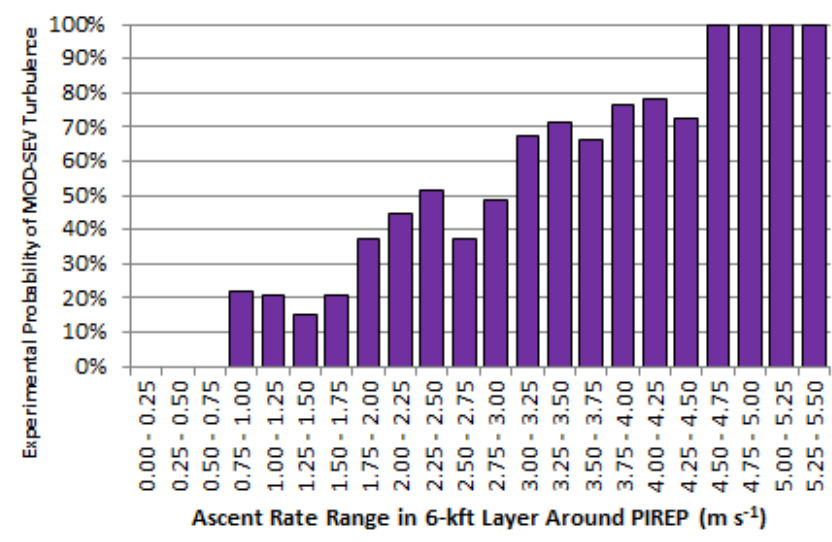

b)

\section{Turbulence Probability Approximation}

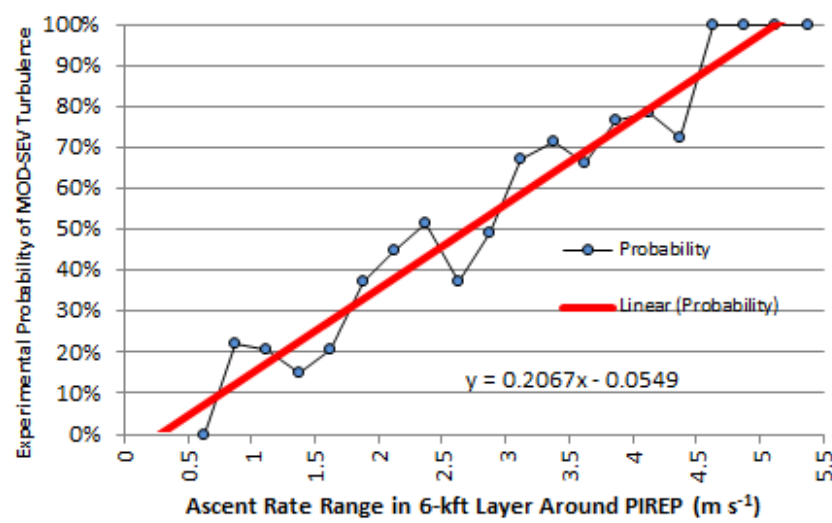

Figure 4. Turbulence probability approximation for (a) the proportion of turbulence to non-turbulence reports, adjusted to reflect equal sample sizes, for ascent rate bins at $0.25-\mathrm{m} \mathrm{s}^{-1}$ increments; and (b) same data as in (a) but for a line graph with a linear regression fit overlaid that shows an increase in turbulence probability of approximately $20 \%$ per $1 \mathrm{~m} \mathrm{~s}^{-1}$ of ascent rate increase.

exceed $30480 \mathrm{~m}$ (100 kft). A preliminary report by Blackmore and Kardell (2012) examined more than a dozen cases of radiosonde ascent rates above $20 \mathrm{~km}$ where there were strong variations in ascent rate. Gravity waves induced by severe thunderstorms were suspected as a common cause for them. Figure 5 shows an example from the Blackmore and Kardell (2012) report. The radiosonde was launched from the NWS upper-air office in Fort Worth, Texas, while large hail and tornadoes were occurring with nearby thunderstorms. Note that above $18288 \mathrm{~m}$ (60 kft) the radiosonde ascent rates varied abruptly in layers less than about 914-m (3-kft) thick. For the most part, classified military aircraft, including unpiloted drones, operate at these altitudes, and thus reports of turbulence affecting the aircraft are not available. 
Dallas Fort Worth (KFWD) 05-25-2011

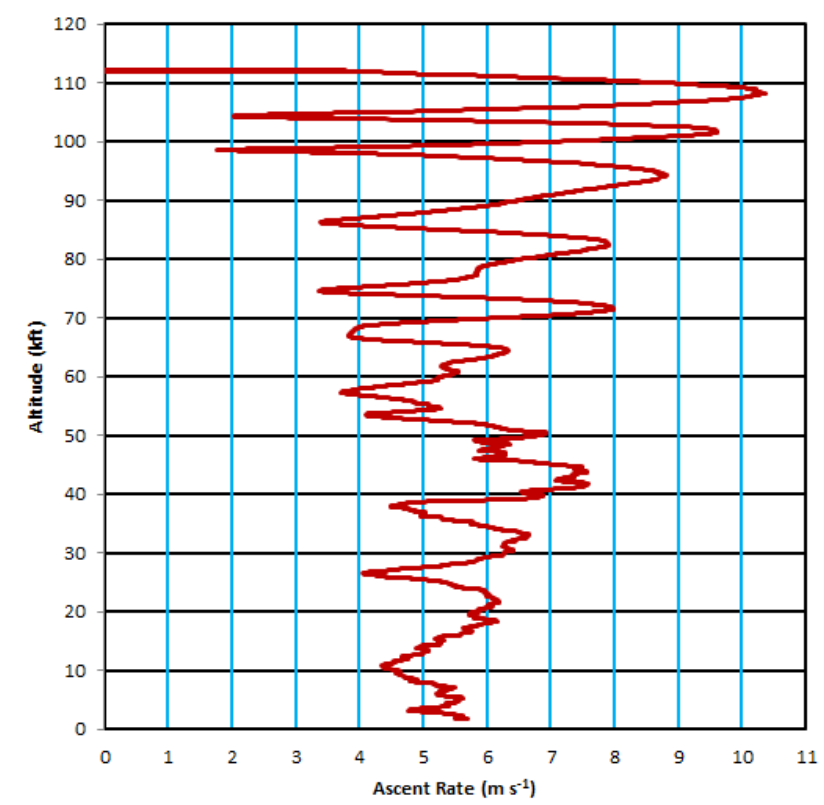

Figure 5. Radiosonde ascent rates observed on 0000 UTC 25 May 2011 during a severe thunderstorm near Fort Worth, TX. The $x$ axis is in $\mathrm{m} \mathrm{s}^{-1}$ and the $y$-axis is in $\mathrm{kft}$.

\section{Conclusions}

Commonly known data obtained from radiosonde observations are PTU, heights, and winds. Yet another measurement of significant value, derived from highresolution data, is the radiosonde ascent rate. It was shown in this study that variations in radiosonde ascent rates in thin layers can indicate the presence of turbulence affecting aircraft. Such data could prove useful in the development of radiosonde-based proxy turbulence observations. These observations could be used to verify turbulence forecasts and provide pilots with turbulence observations in remote areas with few pilot reports or turbulence forecasts. Efforts are underway by the NWS to provide a high-resolution, 1-s RRS radiosonde data product in real-time to all data users. This would include users of the NWS Advanced Weather Interactive Processing System (AWIPS). Each data point would contain the raw and smoothed PTU and height data (derived from PTU and GPS), as well as the latitude and longitude of the radiosonde. In addition, the type of balloon used and the amount of gas used would be included. Note that all NWS upperair offices currently using the RRS can generate radiosonde ascent rate plots and 1-s radiosonde datasets in real-time.
Only the variations in ascent rate were examined in this study. Better approximations of turbulence possibly could be determined by including radiosonde temperature and humidity lapse rates, as well as calculations of wind shear (e.g., the bulk Richardson number) with the ascent rates. Moreover, conclusions from studies on deriving actual vertical air motions and other information from radiosonde ascent rate data date from the 1950s with Corby (1957) to more recent work done by Wang et al. (2009); these studies could be incorporated into further research.

Some cases were found that had little agreement with the PIREP and the variation in ascent rate. Errors in the PIREP or other factors mentioned herein could be a cause. One way to verify this would be to compare radiosonde ascent rates with turbulence model forecasts. The reasons for these discrepancies should be examined further before any effort is made to use radiosonde ascent data for making operational turbulence forecasts.

Last, it was shown that very strong radiosonde ascent variations do occur well above commercial aircraft altitudes and possibly indicate layers of MOD to SEV turbulence. Mostly military aircraft operate at these altitudes. Perhaps radiosonde ascent data could be used to identify turbulence that could affect these aircraft.

Acknowledgments. We thank the staff members of WFO Springfield, Missouri, for their encouragement and input during the research and publication process. Appreciation is extended to the NWA reviewers of this paper for their helpful comments and suggested revisions. We also thank Lisa Monahan, NWS Headquarters, for her administrative assistance in submitting the paper.

\section{REFERENCES}

Blackmore, W. H., and R. Kardell, 2012: Observations of significant variations in radiosonde ascent rates above $20 \mathrm{~km}$. A preliminary report. NWS Headquarters Observing Systems Branch Special Studies, 55 pp. [Available online at www.ua.nws.noaa.gov/Documents/ Radiosonde\%20Ascent\%20Rates.pdf.]

Bower, C. A., Jr., 2005: The evolution and development of the United States National Weather Service universal radiosonde replacement system. Tech Conf. on Meteor. and Environmental Instruments and Methods of Observation (WWW/IO/TECO-2005), Bucharest, Romania, World Meteorological Organization, 2 (12), 5 pp. [Available online at www.wmo.int/pages/prog/ 
www/IMOP/publications/IOM-82-TECO_2005/Papers/ 2(12)_USA 3 Bower.pdf.]

Corby G. A., 1957: A preliminary study of atmospheric waves using radiosonde data. Quart. J. Roy. Meteor. Soc., 83, 49-60, CrossRef.

Federal Aviation Administration (FAA), 2012: Air Traffic Organization Policy, Flight Services. FAA Order JO $7110.10 \mathrm{~V}, 352 \mathrm{pp}$. [Available online at www.faa.gov/ documentLibrary/media/Order/7110.10VBasic.pdf.]

Gallice, A., F. G. Wienhold, C. R. Hoyle, F. Immler, and T. Peter, 2011: Modeling the ascent of sounding balloons: Derivation of the vertical air motion. Atmos. Meas. Tech., 4, 2235-2253, CrossRef.

Hodge, M. W., 1967: Large irregularities of rawinsonde ascensional rates within 100 nautical miles and three hours of reported clear air turbulence. Mon. Wea. Rev., 95, 99-106, CrossRef.
NASDAC, 2004: Review of aviation accidents involving weather turbulence in the United States, 1992-2001. FAA Office of System Safety Reference Number: 04$551,31 \mathrm{pp}$. [Available online at www.asias.faa.gov/i/ turbulence_study_new.pdf.]

Schwartz, B., 1996: The quantitative use of PIREPs in developing aviation weather guidance products. Wea. Forecasting, 11, 372-384, CrossRef.

Wang, J., J. Bian, W. O. Brown, H. Cole, V. Grubišić, and K. Young, 2009: Vertical air motion from T-REX radiosonde and dropsonde data. J. Atmos. Oceanic Technol., 26, 928-942, CrossRef.

Wilks, D. S., 1995: Statistical Methods in the Atmospheric Sciences. Academic Press, 467 pp.

Wolff, J. K., and R. D. Sharman: 2008: Climatology of upper-level turbulence over the contiguous United States. J. Appl. Meteor. Climatol., 47, 2198-2214, CrossRef. 